\title{
Breast Imaging Reporting and Data Systems category 3 (probably benign) breast lesions detected on diagnostic breast ultrasound: The prevalence, outcome and malignancy detection rate in Zaria, Nigeria
}

\begin{tabular}{|c|c|}
\hline \multicolumn{2}{|c|}{$\begin{array}{l}\text { Sefiya A. Olarinoye-Akorede }{ }^{1} \\
\text { Garba H. Yunusa } \\
\text { Halima Aliyu }^{1} \\
\text { Ahmed U. Hamidu }^{1}\end{array}$} \\
\hline \multicolumn{2}{|c|}{$\begin{array}{l}\text { Affiliations: } \\
{ }^{1} \text { Department of Radiology, } \\
\text { Ahmadu Bello University } \\
\text { Teaching Hospital, Nigeria }\end{array}$} \\
\hline \multicolumn{2}{|c|}{$\begin{array}{l}{ }^{2} \text { Department of Radiology, } \\
\text { Unman Dan-Fodiyo } \\
\text { University, Nigeria }\end{array}$} \\
\hline \multicolumn{2}{|c|}{$\begin{array}{l}\text { Corresponding author: } \\
\text { Sefiya Olarinoye-Akorede, } \\
\text { olarinoyebs@yahoo.com }\end{array}$} \\
\hline \multicolumn{2}{|c|}{$\begin{array}{l}\text { Dates: } \\
\text { Received: } 05 \text { Feb. } 2018 \\
\text { Accepted: } 03 \text { Sept. } 2018 \\
\text { Published: } 01 \text { Nov. } 2018\end{array}$} \\
\hline \multicolumn{2}{|c|}{$\begin{array}{l}\text { How to cite this article: } \\
\text { Olarinoye-Akorede SA, } \\
\text { Yunusa GH, Aliyu H, Hamidu } \\
\text { AU. Breast Imaging Reporting } \\
\text { and Data Systems category } 3 \\
\text { (probably benign) breast } \\
\text { lesions detected on diagnostic } \\
\text { breast ultrasound: The } \\
\text { prevalence, outcome and } \\
\text { malignancy detection rate } \\
\text { in Zaria, Nigeria. S Afr J Rad. } \\
\text { 2018; } 22(2) \text {, a1315. https:// } \\
\text { doi.org/10.4102/sajr. } \\
\text { v22i2.1315 }\end{array}$} \\
\hline \multicolumn{2}{|c|}{$\begin{array}{l}\text { Copyright: } \\
\text { (C) 2018. The Authors } \\
\text { Licensee: AOSIS. This } \\
\text { is licensed under the } \\
\text { Creative Commons } \\
\text { Attribution License. }\end{array}$} \\
\hline \multicolumn{2}{|l|}{ Read online: } \\
\hline 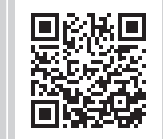 & $\begin{array}{l}\text { Scan this QR } \\
\text { code with your } \\
\text { smart phone or } \\
\text { mobile device } \\
\text { to read online. }\end{array}$ \\
\hline
\end{tabular}

Background: Probably benign breast lesions in the Breast Imaging Reporting and Data Systems (BI-RADS 3) constitute a crucial category and a considerable number of all palpable breast masses. Local data concerning the outcome of such lesions in the Nigerian environment is almost non-existent.

Objectives: The goal of this article is to report the frequency, outcome and malignancy detection rate among palpable breast masses that were categorised on ultrasound as BI-RADS category 3 (probably benign) according to the American College of Radiology (ACR).

Methods: Between January 2015 and July 2017, 603 patients had diagnostic whole-breast ultrasound scans. There were 277 women who complained of palpable breast masses, of whom 151 women were diagnosed as having BI-RADS 3 lesions. The final lesion outcome was determined by either biopsy or ultrasound follow-up examination for a total of 2 years. All data were recorded and analysed with Statistical Package for the Social Sciences (SPSS) version 20 (Chicago, USA).

Results: The frequency of BI-RADS category 3 lesions among all the women who underwent breast ultrasound was 25\% (151/603); and 54\% (151/277) in patients with palpable breast masses. There were 25 patients who were excluded because of incomplete data or who were lost to follow-up. A total of 122 patients had both ultrasound examination and histopathologic diagnosis, while only 4 were followed up for 2 years on ultrasound alone. Of the 122 women biopsied, $117(95.9 \%)$ had benign histologic outcomes, and of the remaining 5, cancer was confirmed in $2(1.6 \%)$, while the remaining 3 patients $(2.5 \%)$ had lesions considered intermediate at histology (juvenile papillomatosis, borderline phylloides and atypical ductal hyperplasia). Three out of four patients who had ultrasound follow-up alone had stable lesions after 2 years, while one patient had complete resolution.

Conclusion: This study found a significantly high biopsy rate of $80 \%(122 / 151)$ for probably benign lesions but a low detection rate for malignancy (1.6\%). Follow-up with imaging rather than biopsy for lesions sonographically described as probably benign, will reduce medical costs and unwarranted invasive procedures.

\section{Introduction}

The 'probably benign' assessment (category 3) in the Breast Imaging Reporting and Data Systems (BI-RADS) is assigned to lesions with specific imaging findings. These include a solid mass with an oval shape, circumscribed margin, parallel orientation, homogenous echo texture and no suspicious malignant characteristics. ${ }^{1,2}$ While these masses have benign imaging features, there is still a low $(<2 \%)$ risk for malignancy. ${ }^{3}$ Radiologists have a key role to play in deciding on the definitive management as to whether the mass should be biopsied or not. The American College of Radiology (ACR) management recommendation is a short-interval imaging follow-up usually at 6, 12 and 24 months, which is considered a reasonable alternative to biopsy. ${ }^{1,4,5,6}$

For the purposes of auditing, a BI-RADS 3 assessment has been reclassified recently by the 5th edition of BI-RADS as audit positive (previously audit negative) for all screening modalities mammography, ultrasound and MRI. ${ }^{7}$ In contrast, for diagnostic imaging, BI-RADS 3 assessment is considered as audit negative. ${ }^{7}$ Nonetheless, there is a general low threshold for biopsy even when the imaging features are benign. ${ }^{8}$ This situation is also observed in Nigeria. 
In this study, we report on the frequency of probably benign breast lesions, the outcome and the detection rate for malignancy in Zaria, with the purpose of reviewing the biopsy-driven practice for masses with benign features.

\section{Materials and methods}

The ethics committee of Ahmadu Bello University Teaching Hospital approved this retrospective review of 603 patients who had whole-breast diagnostic ultrasound examinations between January 2015 and July 2017 (ABUTH/HREC/ D38/2018). Of these, 151 women had palpable breast masses that were classified as probably benign (BI-RADS 3). We excluded 25 patients with incomplete data or loss to followup and finally recruited 126 patients for this study (122 had both ultrasound and biopsy; 4 had ultrasound follow-up alone at 6, 12 and finally 24 months).

High-resolution ultrasound scans of the breasts were performed by the breast radiologists using a Mindray ultrasound machine (DC-8, China), equipped with a $7 \mathrm{MHz}-$ $12 \mathrm{MHz}$ linear transducer. Physical examination of the breast and axilla was performed in the seated position, noting relevant findings before commencing the scan. With the arms raised, each breast was firstly scanned in the supine position for the medial portions of the breast, then in the contralateral posterior oblique position for the lateral breast portion.

Overlapping transverse and longitudinal ultrasound scanning technique, as well as radial and anti-radial scanning was done in real time until the entire breast was scanned. The nipple-areolar complex and lastly the axilla were also examined with ultrasound.

The images were evaluated in a team context by the performing breast radiologists (with 4 and 9 years of experience) using the ACR BI-RADS 4th edition (Ultrasound 1st edition), ${ }^{2}$ the Stavros criteria, ${ }^{3}$ as well as personal experiences in our institution. The cases selected were those that satisfied the criteria for BI-RADS category 3, namely a solid mass with an oval or gently lobulated shape, circumscribed margin, uniform echotexture and a parallel orientation. Complicated cysts were also classified as probably benign. Lesions that were definitely benign like simple cysts and normal lymph nodes were excluded, as were lesions with any suspicious features like irregular margins, antiparallel orientation or posterior shadowing.

The standard of reference for lesion outcome was histopathology or 2 year follow-up (at 6 months, 1 year and 2 years). All data were recorded and analysed using SPSS version 20 (SPSS Inc., Chicago, IL, USA). Figures and tables were used to show descriptive frequency distributions.

\section{Results}

The mean age of the patients was $29.7 \pm 11.3$ years (range 13-68 years). The modal age of the patients was 20-29 years, accounting for $47 \%$ (Table 1 ).
TABLE 1: Age distribution of patients with breast masses diagnosed as probably benign.

\begin{tabular}{lcc}
\hline Age (years) & Frequency & $\mathbf{\%}$ \\
\hline$<19$ & 21 & 13.9 \\
$20-29$ & 71 & 47.0 \\
$30-39$ & 28 & 18.5 \\
$40-49$ & 19 & 12.6 \\
$50-59$ & 10 & 6.6 \\
$60-69$ & 2 & 1.3 \\
\hline Total & $\mathbf{1 5 1}$ & $\mathbf{1 0 0 . 0}$ \\
\hline
\end{tabular}

TABLE 2: Outcome of Breast Imaging Reporting and Data Systems 3 lesions.

\begin{tabular}{lcc}
\hline Lesion outcome & \multicolumn{2}{c}{ Frequency of biopsy findings } \\
\cline { 2 - 3 } & $\boldsymbol{n}$ & $\mathbf{\%}$ \\
\hline Patients sampled for biopsied $(\boldsymbol{n}=\mathbf{1 2 2})$ & 2 & 1.6 \\
$\quad$ Cancers detected & 117 & 95.9 \\
Benign histology & 3 & 2.5 \\
$\quad$ Intermediate & & \\
Patients followed with ultrasound $(\boldsymbol{n}=\mathbf{4})$ & 0 & 0.0 \\
$\quad$ Cancers detected & 1 & 25.0 \\
Resolved and downgraded to BI-RADS 1 & 3 & 75.0 \\
$\quad$ Stable and downgraded to BI-RADS 2 & & \\
\hline
\end{tabular}

BI-RADS, Breast Imaging Reporting and Data Systems.

The frequency of probably benign lesions from this study was $151 / 603(25.0 \%)$. It also constituted $54 \%$, or 151 of the 277 women with palpable lesions. Outcome data were available for 126 patients, which was either histology $(n=122)$ or ultrasound follow-up after initial ultrasound examination at $6,12$ and 24 months $(n=4)$ (Table 2$)$.

Of the 122 patients with histologic confirmation, 117 (95.9\%) had a benign outcome; out of these, 74 (63.24\%) were fibroadenomas (Figure 1). Others, shown in Table 3, included fibrocystic disease, lactating adenoma, benign ductal papilloma, duct ectasia, chronic inflammatory mass, oil cyst (Figures 2a \& 2b) and galactocoele.

Of the remaining five women, three had intermediate (borderline) lesions, which included juvenile papillomatosis, borderline phylloides and atypical ductal hyperplasia. Invasive ductal carcinoma (Figure 3) was detected in the other two women. Overall, the malignancy detection rate from this study was therefore $1.3 \%(2 / 151)$.

The patients who were followed up with ultrasound alone had stable lesions after 2 years $(n=3)$ with no symptoms and were downgraded to BI-RADS 2 (benign). These were fibroadenomas $(n=2)$ and ductal ectasia $(n=1)$. Complete resolution occurred in a patient with Mondor's disease, which was downgraded to BI-RADS 1 (negative).

\section{Discussion}

Probably benign masses are a frequent finding in ultrasound examinations of the breast. It constitutes a problematic category because its definitive management is dependent on whether it is upgraded to malignancy or downgraded to benign. In this study, it accounted for $25 \%$ of all breast ultrasound examinations. This is similar to the reports of $25 \%$ 


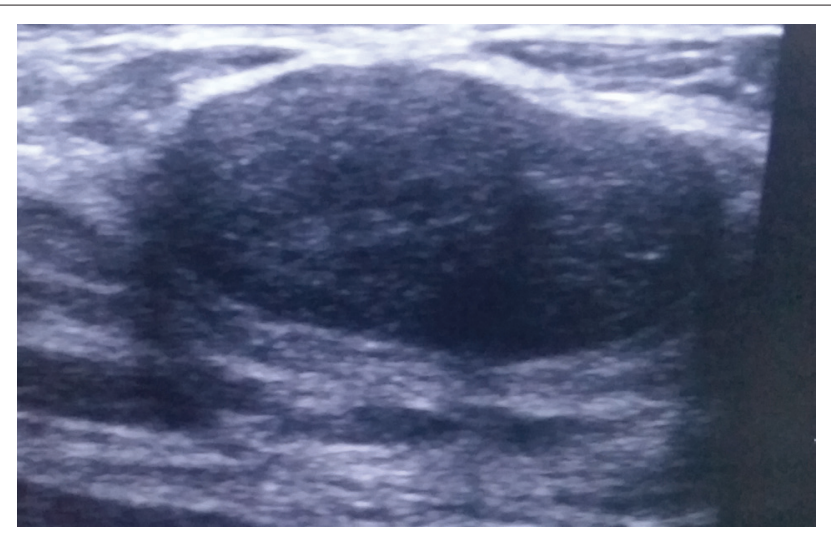

FIGURE 1: Palpable right breast lump in an 18-year-old woman noticed 6 months previously. Ultrasound showed an oval-shaped homogenous hypoechoic mass with well-defined margins. Posterior acoustic enhancement and edge shadowing are seen. Histology confirmed the diagnosis of a fibroadenoma.

\section{TABLE 3: Types of benign breast lesions.}

\begin{tabular}{lcc}
\hline Lesion & $\boldsymbol{n}$ & Frequency (\%) \\
\hline Fibroadenoma & 74 & 63.24 \\
Fibrocystic disease & 12 & 10.25 \\
Ductal ectasia & 7 & 5.98 \\
Abscess or inflammatory & 6 & 5.10 \\
Clustered microcysts & 3 & 2.56 \\
Lactating adenoma & 3 & 2.56 \\
Galactocoele & 3 & 2.56 \\
Fat necrosis & 2 & 1.70 \\
Fibroadenomatoid hyperplasia & 3 & 2.56 \\
Benign ductal papilloma & 4 & 3.41 \\
\hline
\end{tabular}

by Barr et al. ${ }^{9}$ in the USA and $24.9 \%$ by Moon et al. ${ }^{10}$ in Korea. This study constituted mostly younger women between 20 and 29 years old (mean age $29.7 \pm 11.3$; range of $13-68$ years). In other studies, the women were older as reported by Moon et al. (mean 44.5; range 15-78 years); ${ }^{10}$ Park et al. (mean 34, range 12-64 years) ${ }^{8}$ and Harvey et al. (mean 44.4; range $12.2-87.8$ years $).{ }^{11}$

The ACR recommendation for management of BI-RADS 3 lesion is short-term ultrasound follow-up at 6,12 and 24 months., Although very few (four) of our patients were compliant with this recommendation, which spanned 2 years, the lesions that we evaluated with only ultrasound follow-up had benign outcomes as with previous findings of Alimoglu et al. Moon et al. and Raza et al. ${ }^{1,10,12}$ The authors believe that one of the reasons for poor compliance could be the lack of evidence in the community to support low prevalence of malignancy for probably benign breast lesions; hence the high biopsy rate. This study aimed to address this. Also, anxiety from fear of cancer could make patients opt for biopsy, which is quicker, as observed by Harvey et al. ${ }^{11}$ Three of our patients had stable lesions after 2 years, while in one patient the mass completely resolved. In the study by Alimoglu et al. ${ }^{1} 70 \%$ of the lesions remained stable during follow-up, $13.1 \%$ showed interval regression while $14.0 \%$ showed interval progression. They noted that the majority of the interval changes occurred within the first 2 years. In contrast, in the study by Moon et al. 906 out of 920 (98.5\%) turned out benign. ${ }^{10}$
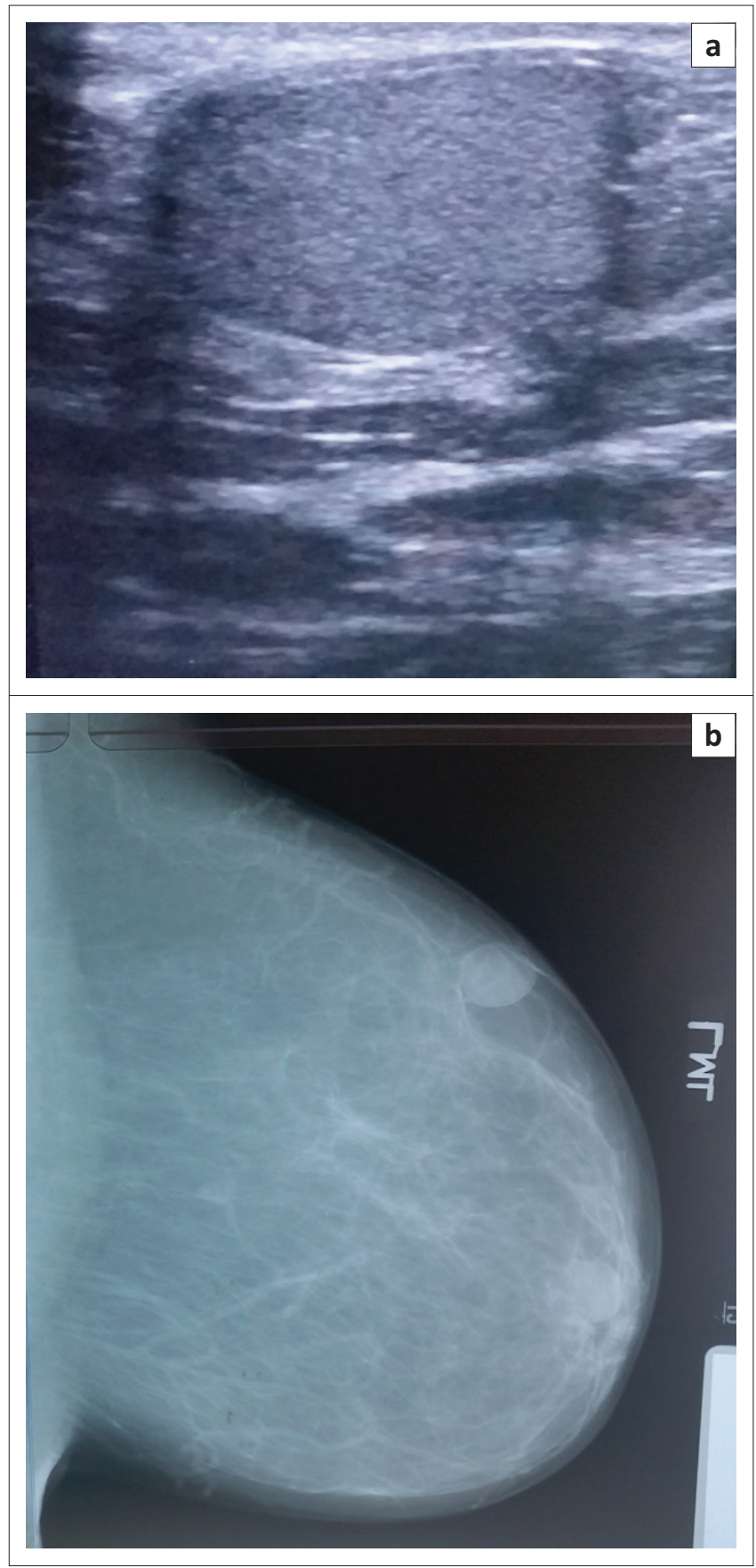

FIGURE 2: A palpable left breast lump in a 48-year-old woman. She had a breast trauma 3 years prior to presentation: (a) Ultrasound of the left breast showed a well-defined hyperechoic mass and (b) left medio-lateral oblique mammogram showing a mass with a calcified (egg shell) rim. At the patient's request, she had a biopsy, which confirmed an oil cyst (from post-traumatic fat necrosis).

The rest of our patients (122 of 126) had tissue sampling. Of these masses, 95\% were histologically benign. The commonest histologic finding was fibroadenoma. This was not surprising given that fibroadenoma is the commonest mass in young African women. Fibrocystic disease is mostly seen in the fourth decade and malignancy in the fifth decade. ${ }^{13}$

The malignancy rate of $1.3 \%$ found in this study correlates with the cancer detection rate of less than $2 \%$ that is associated with breast masses that are categorised as 


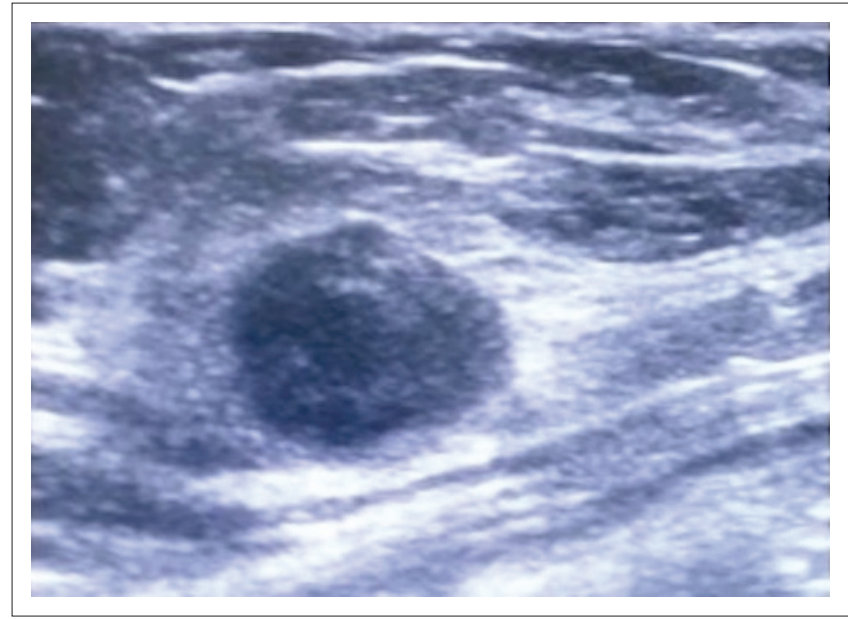

FIGURE 3: Left breast lump in a 44-year-old woman 3 years prior to presentation Ultrasound examination showed a round hypoechoic mass with circumscribed margins and posterior acoustic enhancement. Ultrasound assessment was Breast Imaging Reporting and Data Systems 3 (probably benign). Histologic diagnosis was invasive ductal carcinoma.

probably benign. ${ }^{6,12,14,15}$ Lower cancer detection rates than ours $(0.2 \%, 0.7 \%, 0.8 \%)$ among BI-RADS 3 lesions have been previously reported by Graf et al. Chae et al. and Baum et al. ${ }^{6,16,17}$ However, in these studies, ultrasound was combined with mammography, which improved diagnostic accuracy. MRI BI-RADS category 3 is not frequently used. It is associated with higher malignancy detection rates when compared with ultrasound or mammography. ${ }^{18}$ This is likely because the criteria for MRI BI-RADS category 3 are not well established as it is a relatively new modality.

Our study replicated the fact that the risk for breast cancer is less than 2\% for BI-RADS 3 lesions. When this is considered against the background of significantly higher cost of biopsy in our centre, imaging short-term follow-up would be ideal. Also, unnecessary high tissue sampling of benign masses would be avoided. Initial 6 month ultrasound follow-up will be critical to detect rapidly growing masses because we noticed that our patients' compliance declined with long follow-up intervals.

However, where the patient is not able to return for a followup examination or if imaging is not available to the patient, they should be offered an immediate biopsy. ${ }^{19}$

\section{Conclusion}

Ultrasound is a cost-effective alternative to biopsy for benign breast lesions. However, patients should be carefully assessed before their lesions are assigned to the BI-RADS 3 category. Physicians and radiologists need to explain the goals of follow-up with their patients effectively to ensure better compliance and reduce anxiety.

\section{Limitations}

There were 25 patients who were excluded for loss to followup and incomplete data, thus creating an unavoidable bias. The small sample size limits interpretation. Nonetheless, our results are in accordance with previous studies that involved larger sample sizes.

\section{Acknowledgements Competing interests}

The authors declare that they have no financial or personal relationships that may have inappropriately influenced them in writing this article.

\section{Authors' contribution}

S.A.O-A. and G.H.Y. were responsible for conception and design of the study. S.A.O-A., G.H.Y. and A.U.H. were responsible for critical analysis for intellectual content. H.A. and A.U.H. were responsible for the collection, analysis and interpretation of data. Preparation of the manuscript was done by S.A.O-A. and H.A. All the authors read and approved the final manuscript.

\section{References}

1. Alimoglu E(1), Alimoglu MK, Ceken K, et al. Bi-RADS category 3 nonpalpable breast masses on sonography: Long-term results of a prospective cohort study. I Clin Ultrasound. 2012;40(3):125-134. https://doi.org/10.1002/jcu.21894

2. American College of Radiology. BI-RADS - Ultrasound. 1st ed. In: D'Orsi CJ, Mendelson EB, Ikeda DM, et al. editors. Breast Imaging and Data Systems (BI RADS) atlas. 4th ed. Reston, VA: American College of Radiology, 2003; n.p.

3. Stavros AT, Thickman D, Rapp CL, Dennis MA, Parker SH, Sisney GA. Solid breast nodules: Use of sonography to distinguish between benign and malignant lesions. Radiology. 1995;196(1):123-34. https://doi.org/10.1148/radiology.196.1. lesions. Radic
7784555

4. Giess CS, Smeglin LZ, Meyer JE, Ritner JA, Birdwell RL. Risk of malignancy in palpable solid breast masses considered probably benign or low suspicion: Implications for management. J Ultrasound Med. 2012;31(12):1943-1949. https:// doi.org/10.7863/jum.2012.31.12.1943

5. Graf O, Helbich TH, Fuchsjaeger MH, et al. Follow-up of palpable circumscribed non-calcified solid breast masses at mammography and US: Can biopsy be averted? Radiology. 2004;233(3):850-856. https://doi.org/10.1148/radiol. 2333031845

6. Graf O, Helbich TH, Hopf G, Graf C, Sickles EA. Probably benign breast masses at US: Is follow-up an acceptable alternative to biopsy? Radiology. 2007;244(1): 87-93. https://doi.org/10.1148/radiol.2333031845

7. D'Orsi C, Sickles EA, Mendelson EB, Morris EA. Breast imaging reporting and data system: ACR BI-RADS breast imaging atlas. 5th ed. Reston, VA: American College of Radiology; 2013.

8. Park YM, Kim EK, Lee JH, et al. Palpable breast masses with probably benign morphology at sonography: Can biopsy be deferred? Acta Radiol. 2008;49(10): 1104-1111. https://doi.org/10.1080/02841850802438504

9. Barr RG, Zhang Z, Cormack JB, Mendelson EB, Berg WA. Probably benign lesions at screening breast US in a population with elevated risk: Prevalence and rate of malignancy in the ACRIN 6666 trial. Radiology. 2013; 269(3):701-712. https://doi. org/10.1148/radiol.13122829

10. Moon HJ, Kim MJ, Kwak JY, Kim EK. Probably benign breast lesions on ultrasonography: A retrospective review of ultrasonographic features and clinical factors affecting the BI-RADS categorization. Acta Radiol. 2010;51(4):375-382. https://doi.org/10.3109/02841851003662780

11. Harvey JA, Nicholson BT, Lorusso AP, Cohen MA, Bovbjerg VE. Short-term followup of palpable breast lesions with benign imaging features: Evaluation of 375 lesions in 320 women. Am J Roentgenol. 2009;193(6):1723-1730. https://doi. org/10.2214/AJR.09.2811

12. Raza S, Chikarmane SA, Neilsen SS, Zorn LM, Birdwell RL. BI-RADS 3,4 , and 5 lesions: Value of US in management-follow-up and outcome. Radiology. 2008;248(3):773-781. https://doi.org/10.1148/radiol.2483071786

13. Santen RJ, Cerilli LA, Harvey JA. The breast: Gynecomastia and benign breast disease in women. In: Besser GM, Thorner MO, editors. Comprehensive clinical endocrinology. London: Elsevier Science, 2002; p. 585-612.

14. Heinig J, Witteler R, Schmitz R, Kiesel L, Steinhard J. Accuracy of classification of breast ultrasound findings based on criteria used for BI-RADS Ultrasound. Ultrasound Obstet Gynecol. 2008;32(4):573-578. https://doi.org/10.1002/uog.5191

15. Kim EK, Ko KH, Oh KK, et al. Clinical application of BI-RADS final assessment to breast sonography in conjunction with mammography. Am J Roentegenol. 2008;190(5):1209-1215. https://doi.org/10.2214/AJR.07.3259 
16. Chae EY, Cha JH, Shin HJ, Choi WJ, Kim HH. Reassessment and follow-up results of BI-RADS category 3 lesions detected on screening breast ultrasound. Am J Roentgenol. 2016;206(3):666-672. https://doi.org/10.2214/AJR.15.14785

17. Baum JK, Hanna LG, Acharyya S, et al. Use of BI-RADS 3 probably benign category in the American college of radiology imaging network digital mammographic imaging screening trial. Radiology. 2011;260(1):61-67.
18. Grimm LJ, Anderson AL, Baker JA, et al. Frequency of malignancy and imaging characteristics of probably benign lesions seen at MRI. AJR Am J Roentgenol. 2015;205(2):442-447. https://doi.org/10.2214/AJR.14.13530

19. American College of Radiology. Breast imaging reporting and data systemmagnetic resonance imaging (BI-RADS-MRI). 1st ed. Reston, VA: American College of Radiology; 2003. 